\title{
Design of Bimodal Ligands of Neurotensin Receptor 1 for PET Imaging and Fluorescence-Guided Surgery of Pancreatic Cancer
}

\author{
Emma Renard, ${ }^{\dagger}$ Pierre-Alix Dancer, ${ }^{,}$Christophe Portal, ${ }^{\S}$ Franck Denat,,${ }^{\dagger}$ Aurélie Prignon,,${ }^{* \star}$ and \\ Victor Goncalves*i†
}

†Institut de Chimie Moléculaire de l’Université de Bourgogne, UMR CNRS 6302, Université Bourgogne FrancheComté, 21000, Dijon, France

${ }^{\sharp}$ Kaer Labs, 44300, Nantes, France

§Edinburgh Molecular Imaging, EH16 4UX, Edinburgh, United Kingdom

‡Sorbonne Université, UMS28, Laboratoire d’Imagerie Moléculaire Positonique (LIMP), 75020, Paris, France

KEYWORDS: Neurotensin; fluorescence-guided surgery; positron emission tomography; dual-modality; gallium-68

\begin{abstract}
Neurotensin receptor 1 (NTSR1) is overexpressed in most human pancreatic ductal adenocarcinomas. It makes it an attractive target for the development of pancreatic cancer imaging agents. In this study, we sought to develop a bimodal PET-fluorescent imaging agent capable of specifically targeting these receptors. Starting from the structure of a known NTSR1 agonist, a series of tracers was synthesized, radiometalated with gallium- 68 and evaluated in vitro and in vivo, in mice bearing an AsPC-1 xenograft. PET imaging allowed us to identify the compound $\left.{ }^{68} \mathrm{Ga}\right] \mathrm{Ga}-\mathrm{NODAGA}-$ Lys(Cy5**)-AEEAc-[Me-Arg8, Tle $\left.{ }^{12}\right]-\mathrm{NT}(7-13)$ as the one with the most promising biodistribution profile, characterized by high tumor uptake $(2.56 \pm 0.97 \% \mathrm{ID} / \mathrm{g}, 1 \mathrm{~h}$ p.i. $)$ and rapid elimination from non-targeted organs, through urinary excretion. Fluorescence imaging gave similar results. On this basis, fluorescence-guided resection of tumor masses was successfully carried out on a preclinical model.
\end{abstract}

\section{INTRODUCTION}

Pancreatic ductal adenocarcinoma (PDAC), commonly referred to as pancreatic cancer, is the fourth leading cause of death by cancer in Europe., ${ }^{1,2}$ This cancer has a poor prognosis, with a survival rate of only $8 \%$ at five years, which results from the late clinical presentation of the patients, rapid progression of the disease, and limited efficacy of chemotherapy. ${ }^{2,3}$ Only patients with a localized, non-metastatic tumor ( $10 \%$ to $20 \%$ ), can benefit from surgery. Unfortunately, their selection is difficult because anatomical imaging is weakly effective in detecting local tumor invasion and small metastases. In addition, about 30 to $50 \%$ of these patients will relapse. ${ }^{4}$ Indeed, the precise evaluation of tumor margins, during surgery or histopathological examination of tissue samples, is challenging, which can lead to incomplete tumor resection. The presence of residual tumor cells after surgery is a strong predictor of tumor recurrence. ${ }^{5}$ Therefore, there is a real clinical need to identify new methods that improve both the diagnosis and staging of pancreatic cancer and the accuracy of surgical procedures.
Positron emission tomography (PET) is a nuclear imaging technique that has been widely adopted as a standard tool for diagnosing and staging patients in oncology. ${ }^{6} \mathrm{PET}$ allows the efficient and quantitative detection of tumors, but suffers from a limited spatial resolution. Fluorescence-guided surgery (FGS) is another fast-growing field which has already achieved clinical success. It relies on fluorescence imaging, a highly resolutive and sensitive imaging modality, which has been shown to improve the quality of tumor resection during the surgical procedure. ${ }^{7-10}$

An attractive strategy for locating primary tumors and their possible metastases is based on the use of bimodal nuclear/optical probes. ${ }^{11,12}$ By combining both modalities into a single imaging agent, it is possible to assess the extent of the disease before and after surgery by PET imaging, while fluorescence imaging can be used during surgery to delineate the local spread of the tumor and detect the presence of metastases invisible to the naked eye.

A well-validated marker of pancreatic cancer is neurotensin receptor 1 (NTSR1). ${ }^{13}$ NTSR1 is overexpressed in 75$88 \%$ of pancreatic adenocarcinomas and high-grade pre- 
cancerous lesions (PanINs) but is not detected in healthy pancreas or pancreatitis. ${ }^{14}$ Thus, unlike glucose transporters for instance, NTSR1 tracers allow the imaging of malignant pancreatic tumors and related metastases with high specificity. ${ }^{15-17}$ Neurotensin (NT) is the endogenous ligand of NTSR1. Its smallest active fragment, NT(8-13), has nanomolar affinity for the receptor. ${ }^{18,19}$ Because of its limited half-life in vivo, several derivatives were developed to limit proteolytic degradation. ${ }^{20}$ A NT(6-13) ana$\log$, named NT-20.3, showed an excellent affinity for NTSR1 $\left(\mathrm{IC}_{50}=2.2 \pm 0.3 \mathrm{nM}\right) .{ }^{21}$ In 2011, Alshoukr et al. radiolabeled the peptide NT-20.3 with gallium- $68\left({ }^{68} \mathrm{Ga}\right)$ using DOTA as a chelating agent. This compound showed specific tumor uptake in vivo, with high tumor-to-organ ratios, in a model of NTSR1-positive colorectal cancer. ${ }^{22}$ These results were further confirmed in 2019 by Prignon et al. in subcutaneous and orthotopic models of pancreatic cancer. ${ }^{23}$

To date, only one bimodal PET/fluorescent imaging agent targeting NTSR1 has been reported by the group of Deng and collaborators. ${ }^{24}$ This compound, which incorporates a DOTA chelator for copper- $64\left({ }^{64} \mathrm{Cu}\right)$ and a cyanine 5.5 dye, showed a good affinity for the human colon adenocarcinoma cell model, HT-29. Unfortunately, its pharmacokinetic properties are suboptimal, with a significant liver clearance, which was attributed to the hydrophobicity of

\section{Scheme 1. Synthesis of bimodal NTSR1 ligands}

the fluorophore and/or the release of free ${ }^{64} \mathrm{Cu}$ from the chelator in vivo. ${ }^{25}$

In this study, we report the development and evaluation of a series of PET/fluorescent imaging agents targeting NTSR1-positive tumors. These compounds were designed to chelate ${ }^{68} \mathrm{Ga}$, a positron-emitting radioisotope with a half-life of $67.7 \mathrm{~min}$, well-adapted to the pharmacokinetics of small peptides. Starting from the neurotensin analog NT-20.3, different near-infrared (NIR) fluorescent probes and spacers were tested in order to optimize the biodistribution of the imaging agents. The best compound was validated in vivo by PET and NIR fluorescence imaging in mice xenografted with an AsPC-1 model of human pancreatic ductal adenocarcinoma. The selectivity of the imaging agent was further confirmed during the fluorescence-guided resection of tumor masses in the same mouse model.

\section{RESULTS AND DISCUSSION}

Design of NTSR1 ligands. A series of bimodal agents was synthesized (Scheme 1). Their structure derives from the sequence of the well-validated peptide agonist NT20.3 (Ac-Lys-Pro-N-Me-Arg-Arg-Pro-Tyr-Tle-Leu-OH). ${ }^{21-}$ ${ }^{23,26} \mathrm{~A}$ lysine residue was introduced at the $\mathrm{N}$-terminal end of the peptide to conjugate the radiometal chelator and the fluorophore, and different spacers were inserted before the lysine: no spacer, a PEG2 analog (8-amino-3,6-dioxaoctanoic acid, AEEAc) or a $\mathrm{PEG}_{4}$ chain.
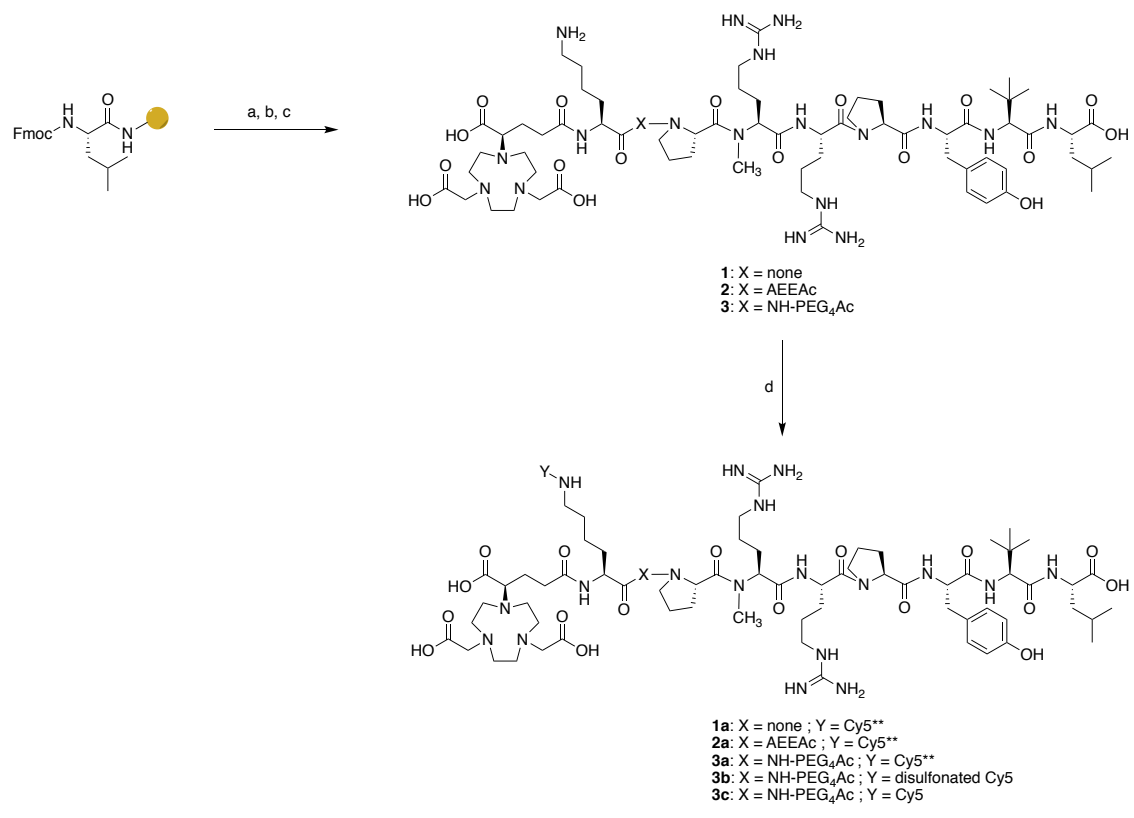

aReagents and conditions: (a) Coupling: Fmoc-(L)-aa(PG)-OH, DIC, Oxyma, DMF, MW. Deprotection: piperidine 20\% (v/v) in DMF, MW; (b) (R)-NODAGA-NHS, DIPEA, DMF, RT, 18 h; (c) TFA/triisopropylsilane/ $\mathrm{H}_{2} \mathrm{O}(95 / 2.5 / 2.5, v / v / v)$ RT, 2 h, then $40^{\circ} \mathrm{C}, 4 \mathrm{~h}$; (d) Cy5 derivatives, DIPEA, TSTU, DMF, RT, $20 \mathrm{~h}$. aa: amino acid; PG: protecting group; AEEAc: 8-amino-3,6-dioxaoctanoic acid. 
For the PET modality, we chose to use ${ }^{68} \mathrm{Ga}$ among other positron-emitting radioisotopes because its short physical half-life matches well with the rapid pharmacokinetics of peptides, and it provides safer dosimetry for the patients compared to ${ }^{64} \mathrm{Cu} .{ }^{27}$ In combination with its good availability, limited cost of operation, and the reliability of commercial ${ }^{68} \mathrm{Ge} /{ }^{68} \mathrm{Ga}$ generators, ${ }^{68} \mathrm{Ga}$ is one of the most interesting radioisotopes for PET diagnosis today. $(R)$ NODAGA was chosen as the chelator. ${ }^{28}$ This polyazamacrocycle is well-adapted to metals with small ionic radii such as ${ }^{68} \mathrm{Ga}$ and ${ }^{64} \mathrm{Cu} .{ }^{29}$ It requires mild radiolabeling conditions and forms highly stable complexes in vivo.

For the fluorescent modality, three near-infrared cyanine 5 derivatives, which differ in the number of sulfonate groups, were tested: a cyanine with no sulfonate group (Cy5), ${ }^{30}$ a disulfonated cyanine 5,31-33 and a tetrasulfonated cyanine $\left(\mathrm{Cy}^{* *}\right),{ }^{34}$ which has already shown promising results in a clinical setting.

Synthesis of the ligands. The different bimodal ligands were synthesized in four steps (Scheme 1). First, the peptide was elongated by solid phase peptide synthesis (SPPS), starting from Fmoc-Leu Wang preloaded resin. ${ }^{35}$ The different spacers were then introduced at this stage in $N$-terminal position, prior to the coupling of a lysine residue. ( $R$ )-NODAGA-NHS was then conjugated to the free $\alpha$-amine of the $N$-terminal lysine. Cleavage and deprotection of the peptides from the resin, followed by RP-HPLC purification of the crude products, afforded compounds 1, 2, and 3 in $43 \%$ to $69 \%$ yield. Finally, the different fluorophores were activated with TSTU and coupled to the $\varepsilon$-amine group of the lysine yielding the NTSR1 ligands 1a, 2a, 3a, 3b, 3c in 18\% to $48 \%$ yield after RP-HPLC purification.

Spectral properties and stability. UV-Vis absorbance and fluorescence spectra were recorded in phosphate buffer $(0.01 \mathrm{M})$ at $\mathrm{pH}$ 7.4. The $\lambda_{\text {exc }}$ ranged between 643 and 653 $\mathrm{nm}$ and the $\lambda_{\mathrm{em}}$ between 655 and $666 \mathrm{~nm}$, with a Stokes shift of $c a .12 \mathrm{~nm}$. No aggregation of the fluorescent dyes was observed in aqueous buffered solution (Figure S9S11).

The stability of the molecules with regard to enzymatic degradation was then evaluated in mouse serum at $37^{\circ} \mathrm{C}$ by RP-HPLC. No significant evolution was observed over $24 \mathrm{~h}$ of incubation for the peptides $\mathbf{1 a}, \mathbf{2} \mathbf{a}, \mathbf{3 a}, \mathbf{3} \mathbf{b}$ and $\mathbf{3 c}$ (Figures S18-S22). In contrast, only half of the natural neurotensin was recovered after five hours of incubation in these assay conditions (Figure S17).

In Vitro Binding Affinity. The five compounds were then metalated with ${ }^{\text {nat }} \mathrm{Ga}$. Their $K_{\mathrm{i}}$ was determined in a competition experiment performed on $\mathrm{CHO}$ cells overexpressing NTSR1 receptor, using [ $\left.{ }^{125} \mathrm{I}\right] \mathrm{I}-\mathrm{Tyr}^{3}$-neurotensin as ligand. ${ }^{36}$ All $K_{\mathrm{i}}$ values were close to the one of the refer-

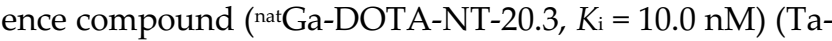
ble 1). Interestingly, the spacer appears to play only a minor role in the affinity of ligands for their target, with the exception of the compound bearing a AEEAc chain natGa2a, whose affinity was reduced by a factor of 2 compared to the compounds with no spacer or a PEG4 spacer (nat $\mathrm{Ga}$ 1a and nat Ga-3a respectively). In contrast, the number of sulfonates had a greater impact on ligand affinity: the absence of sulfonate groups on the cyanine was associated with a stronger binding affinity $\left(K_{\mathrm{i}}\right.$ of $0.76 \mathrm{nM}$ for the nonsulfonated Cy5 ${ }^{\text {nat }} \mathrm{Ga}-3 \mathrm{c}$ versus $6.02 \mathrm{nM}$ for the tetrasulfonated $\left.\mathrm{Cy}^{* *}{ }^{\text {nat }} \mathrm{Ga}-3 \mathrm{a}\right)$. We hypothesize that these results can be explained by the establishment of non-specific hydrophobic interactions between the Cy5 fluorophore and NTSR1.

Radiolabeling. The compounds were radiolabeled with $\left[{ }^{68} \mathrm{Ga}\right] \mathrm{GaCl}_{3}$ in sodium acetate buffer $(0.8 \mathrm{M}, \mathrm{pH} 3.5)$ for 10 min at $40{ }^{\circ} \mathrm{C}$. Radiochemical yields ranged from $51 \%$ to $90 \%$ and molar activities from $3.5 \mathrm{MBq} / \mathrm{nmol}$ to 10.7 $\mathrm{MBq} / \mathrm{nmol}$ at the end of the radiolabeling (Table S1). The peptides were purified on a $\mathrm{C}_{18}$ Sep-Pack cartridge to achieve a radiochemical purity superior to $99 \%$ for each tracer, as determined by radio-HPLC analyses. The radiolabeling, quality control and intravenous injection of peptides were completed in less than $1 \mathrm{~h}$. Partition coefficients $(\log \mathrm{D})$ were determined by the shake-flask method in presence of octanol and PBS $(0.1 \mathrm{M})$ at $\mathrm{pH} 7.4$ (Table 1). ${ }^{37}$ As expected, the five bimodal agents were all rather hydrophilic. Compounds $\left[{ }^{68} \mathrm{Ga}\right] \mathrm{Ga} 1 \mathrm{a},\left[{ }^{68} \mathrm{Ga}\right] \mathrm{Ga} 2 a$ and ${ }^{68} \mathrm{Ga}$ Ga3a showed the same $\log \mathrm{D}$ (ca. -2.6), suggesting that the hydrophilicity of these molecules is mainly driven by the number of sulfonate groups on the cyanine rather than by the length of the spacer.

Table 1. Inhibition constant and partition coefficient of compounds tested in this study.

\begin{tabular}{|c|c|c|}
\hline Compound & $K i(n M)^{a}$ & $\log D^{b}$ \\
\hline$\left[{ }^{\mathrm{nat} / 68} \mathrm{Ga}\right] \mathrm{Ga} 1 \mathrm{a}$ & $5.52[4.8-6.4]$ & $-2.63 \pm 0.10$ \\
\hline$\left[{ }^{\text {nat } / 68} \mathrm{Ga}\right] \mathrm{Ga} 2 a$ & $12.1[10.3-14.2]$ & $-2.51 \pm 0.16$ \\
\hline$\left[{ }^{\text {nat/68 }} \mathrm{Ga}\right] \mathrm{Ga} 3 \mathbf{a}$ & $6.02[4.9-7.4]$ & $-2.73 \pm 0.13$ \\
\hline$\left[{ }^{\text {nat } / 68} \mathrm{Ga}\right] \mathrm{Ga} 3 \mathrm{~b}$ & $3.81[2.9-5.0]$ & $-2.29 \pm 0.06$ \\
\hline$\left[{ }^{\mathrm{nat} / 68} \mathrm{Ga}\right] \mathrm{Ga} 3 \mathrm{c}$ & $0.76[0.66-0.88]$ & $-0.70 \pm 0.25$ \\
\hline$\left.{ }^{\mathrm{nat} / 68} \mathrm{Ga}\right] \mathrm{Ga}-\mathrm{DOTA}-\mathrm{NT}-20.3$ & $10.0[6.51-15.4]^{c}$ & $-2.50 \pm 0.31$ \\
\hline
\end{tabular}

${ }^{a} K_{\mathrm{i}}$ values are presented as "mean [95\% confidence intervall" and were determined using natGa-compounds and $\left.{ }^{125} \mathrm{I}\right] \mathrm{I}-\mathrm{Tyr}^{3}$-neurotensin $\left(0.05 \mathrm{nM}, K_{\mathrm{d}}=0.22 \mathrm{nM}\right)$ as the radioligand. bPartition coefficients $(\mathrm{Log} \mathrm{D})$ at $\mathrm{pH} 7.4$ were determined using ${ }^{68} \mathrm{Ga}$-compounds and are presented as mean \pm SD. 'Alshoukr et al. reported an $\mathrm{IC}_{50}$ value of $14 \pm 2 \mathrm{nM}$ in a competition assay on HT29 cells. ${ }^{22}$ 
PET Imaging and Biodistribution. In order to assess their pharmacokinetic properties, each radiolabeled bimodal tracer was first injected (473 \pm 151 pmol, $3.49 \pm 2.71 \mathrm{MBq})$ into five healthy nude mice. Dynamic PET imaging was performed for $70 \mathrm{~min}$ immediately post-injection.

As illustrated in Figure 1, compounds $\left[{ }^{68} \mathrm{Ga}\right] \mathrm{Ga} 1 \mathrm{a}$, $\left[{ }^{68} \mathrm{Ga}\right] \mathrm{Ga} 2 \mathrm{a}$, and $\left[{ }^{68} \mathrm{Ga}\right] \mathrm{Ga3a}$ showed a conventional urinary excretion profile, with the majority of the radioactive signal located in the kidneys and bladder. In contrast, compound $\left.{ }^{68} \mathrm{Ga}\right] \mathrm{Ga} 3 \mathbf{b}$ also showed signal uptake in the heart and liver, suggesting a longer circulation time in the bloodstream, and clearance of the compound, in part by the hepatic pathway. Finally, the injection of the least hydrophilic compound, $\left[{ }^{68} \mathrm{Ga}\right] \mathrm{Ga} 3 \mathrm{c}$, resulted in significant uptake into the liver. Thus, the presence of four sulfonate groups on the cyanine 5 is essential to achieve a good distribution profile. The length of the spacer did not alter significantly the distribution of this series of NTSR1 ligands.

Thus, further experiments on the tetrasulfonated-compounds $\left(\left[{ }^{68} \mathrm{Ga}\right] \mathrm{Ga} 1 \mathrm{a},{ }^{\left.6{ }^{68} \mathrm{Ga}\right] \mathrm{Ga} 2 a}\right.$ and $\left.\left[{ }^{68} \mathrm{Ga}\right] \mathrm{Ga} a\right)$ were carried out on a model of human pancreatic adenocarcinoma (AsPC-1), xenografted subcutaneously on the shoulder of nude mice. Static PET images were recorded 40 minutes post-injection of $553 \pm 145$ pmol, $3.17 \pm 0.92$ $\mathrm{MBq}$, over 15 minutes $(\mathrm{n}=3$ ) (Figure $2 \mathrm{~A})$. Tumors were clearly visualized with a high tumor-to-background contrast, even if compound $\left.{ }^{68} \mathrm{Ga}\right] \mathrm{Ga} a$ showed poorer tumor uptake compared to $\left[{ }^{68} \mathrm{Ga}\right] \mathrm{Ga} 1 \mathrm{a}$ and $\left[{ }^{68} \mathrm{Ga}\right] \mathrm{Ga} 2 \mathrm{a}$.

In order to confirm these results, an ex vivo biodistribution study was performed. One hour after the injection, mice
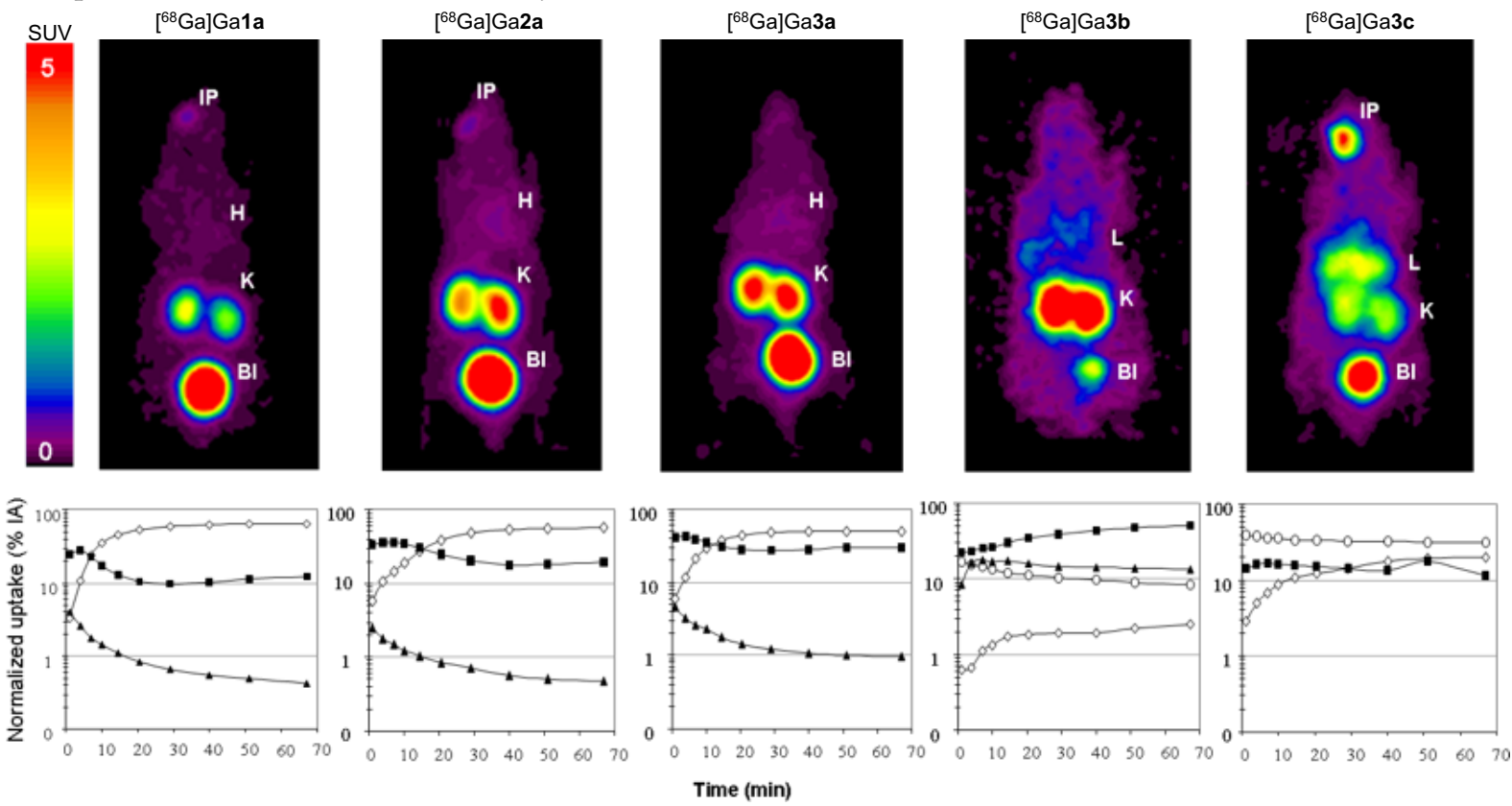

Figure 1. (Top) Maximum intensity projection (MIP) images obtained after $10 \mathrm{~min}$ of signal acquisition, between 5767min p.i., during a dynamic PET imaging study, after the retro-orbitary injection in the sinus vein of [ $\left.{ }^{68} \mathrm{Ga}\right] \mathrm{Ga1a}$, $\left.\left[{ }^{68} \mathrm{Ga}\right] \mathrm{Ga} 2 \mathrm{a},{ }^{[68} \mathrm{Ga}\right] \mathrm{Ga3a},\left[{ }^{68} \mathrm{Ga}\right] \mathrm{Ga} 3 \mathbf{b}$ and $\left.{ }^{68} \mathrm{Ga}\right] \mathrm{Ga3c}$. SUV: 3D Standardized Uptake Value data; IP : injection point; $\mathrm{H}$ : heart; K : kidneys; $\mathrm{Bl}$ : Bladder. (Bottom) Image-derived time activity curves (TACs) for radioactivity in the bladder (open diamonds), kidneys (filled squares), heart (filled triangles) and liver (open circles). 
$\left[{ }^{68} \mathrm{Ga}\right] \mathrm{Ga1a}$

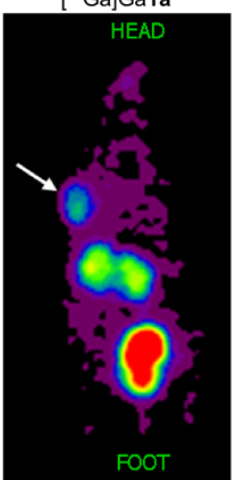

$\left[{ }^{68} \mathrm{Ga}\right] \mathrm{Ga} 2 \mathrm{a}$

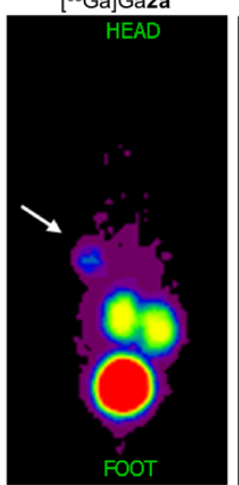

$\left[{ }^{68} \mathrm{Ga}\right] \mathrm{Ga3a}$

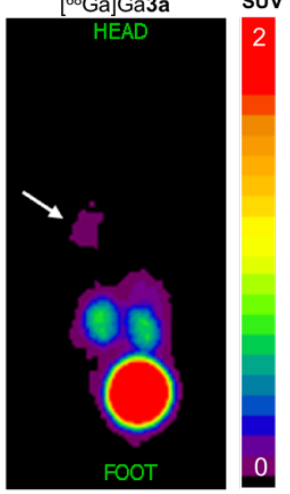

B

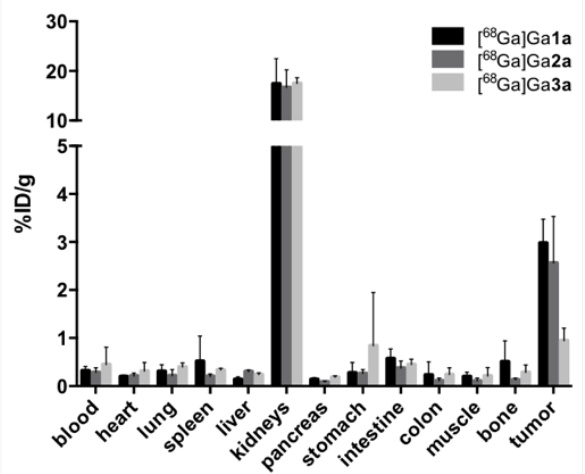

C

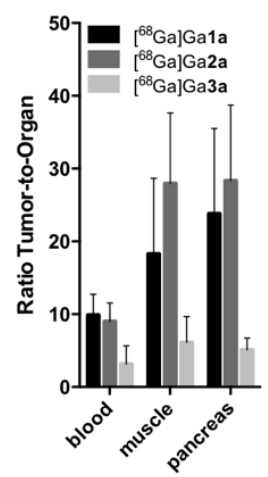

Figure 2. (A) Representative PET images of AsPC-1 tumor-bearing mice. The images show the maximum intensity projections, recorded over $15 \mathrm{~min}$ acquisition, $40-55 \mathrm{~min}$ p.i. of $\left.\left[{ }^{68} \mathrm{Ga}\right] \mathrm{Ga} 1 \mathrm{a},{ }^{68} \mathrm{Ga}\right] \mathrm{Ga} 2 \mathrm{a}$ and $\left[{ }^{68} \mathrm{Ga}\right] \mathrm{Ga} \mathbf{a}$. The location of the xenografted tumor is indicated by a white arrow. (B) Ex vivo biodistribution data of $\left.{ }^{68} \mathrm{Ga}\right] \mathrm{Ga} 1 \mathrm{a},\left[{ }^{68} \mathrm{Ga}\right] \mathrm{Ga} a \mathrm{a}$ and $\left.{ }^{68} \mathrm{Ga}\right] \mathrm{Ga3a} 1 \mathrm{~h}$ p.i. Values are expressed in percentage of injected dose per gram $(\% \mathrm{ID} / \mathrm{g}$, mean $\pm \mathrm{SD})$ for each collected organ. (C) Tumor-to-organ ratios from ex vivo biodistribution. Data are expressed as means \pm SD.

On average, the injection of $\left[{ }^{68} \mathrm{Ga}\right] \mathrm{Ga} 2 \mathrm{a}$ resulted in tumorto-normal tissue ratios higher than $\left.{ }^{68} \mathrm{Ga}\right] \mathrm{Ga} a$ a (Figure $2 \mathrm{C})$, which prompted us to select this tracer for the remainder of the study.

Near-Infrared Fluorescence Imaging and FluorescenceGuided Surgery. Fluorescence images were recorded $1 \mathrm{~h}$, $3 \mathrm{~h}$ and $24 \mathrm{~h}$ after intravenous administration of different amounts of compound 2 a (50 pmol, 500 pmol and 5 nmol). Mice were euthanized, organs collected, and the uptake of the tracer was quantified by fluorescence imaging at $680 \mathrm{~nm}$ (Figure 3, Table S3, Figure S23). In accordance with PET images, the signal was mainly present in the tumor and kidneys. We also noticed fluorescence in the digestive organs, which actually came from the food ingested by the mice. In the other tissues, signal was minimal (Figure 3A).

It is worth noting that the signal in the tumor increased with the injected dose, while it remained about the same in muscles and pancreas. This led to improved tumor-to-
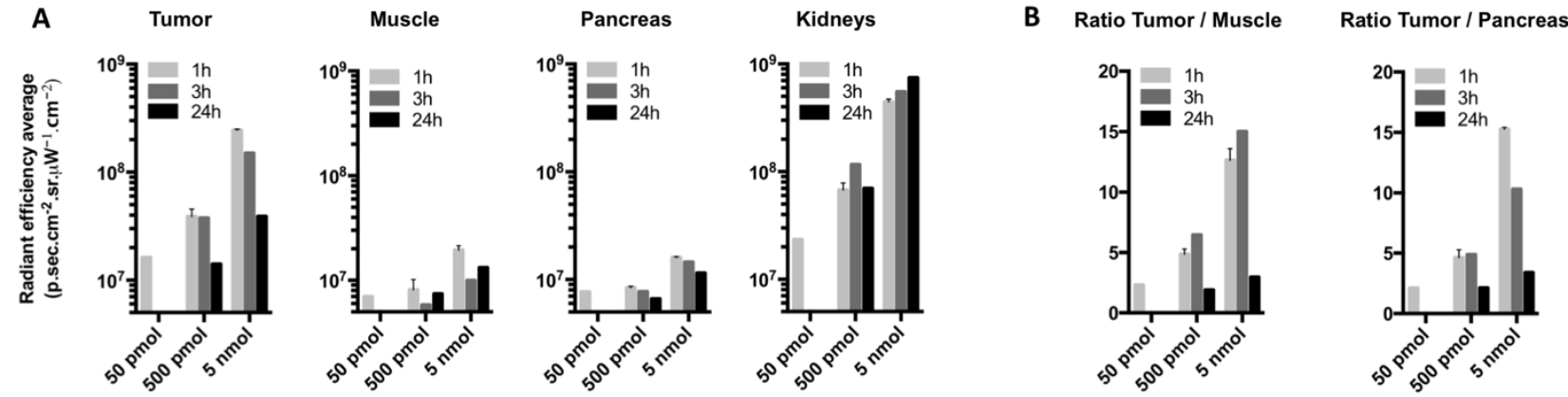

Figure 3. (A) Ex vivo biodistribution of $2 \mathrm{a}(50 \mathrm{pmol}, 500 \mathrm{pmol}$ and $5 \mathrm{nmol})$ at $1 \mathrm{~h}, 3 \mathrm{~h}$ and $24 \mathrm{~h}$ p.i. by fluorescence imaging. Data are expressed as means of the average radiant efficiency $\left(\left[\mathrm{p} / \mathrm{s} / \mathrm{cm}^{2} / \mathrm{sr}\right] /\left[\mu \mathrm{W} / \mathrm{cm}^{2}\right]\right)$ for each collected organ. (B) Tumor-to-organ ratios from ex vivo biodistribution. Individual data are available in SI, Table S3. Data could not be collected for the 50 pmol dose at $3 \mathrm{~h}$ and $24 \mathrm{~h}$ p.i. due to insufficient signal. 

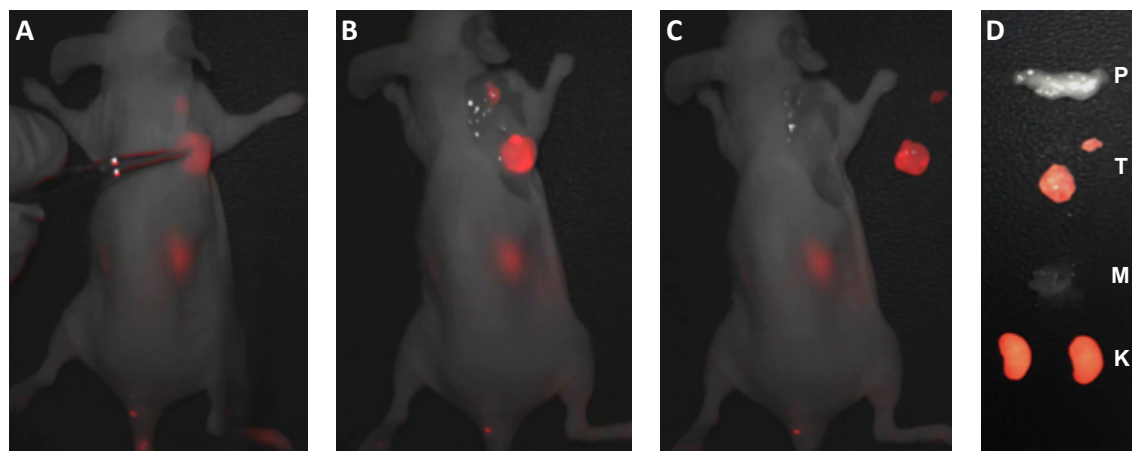

Figure 4. (A-C) Illustrative fluorescence-guided surgery of a mouse bearing an AsPC-1 tumor, 3.5 hours p.i. of $2 a$ (500 pmol). (D) Fluorescence imaging of isolated organs. P: pancreas, T: tumors, M: muscle, K: kidneys. Images were recorded with an exposure time of $200 \mathrm{~ms}$, a laser excitation at $640 \mathrm{~nm}$ and collection of fluorescence emission above $665 \mathrm{~nm}$.

Through the stepwise evaluation of different near-infrared fluorophores and spacers, we were able to identify the tracer $\quad\left[{ }^{68} \mathrm{Ga}\right] \mathrm{Ga} 2 \mathrm{a}, \quad\left[{ }^{68} \mathrm{Ga}\right] \mathrm{Ga}-N O D A G A-L y s\left(C y 5^{* *}\right)$ AEEAc-[Me-Arg8, Tle $\left.{ }^{12}\right]-\mathrm{NT}(7-13)$, as the one with the most interesting distribution, similar to that of $\left[{ }^{68} \mathrm{Ga}\right] \mathrm{Ga}-$ DOTA-NT-20.3. This bimodal compound showed rapid and high tumor uptake, fast clearance from circulation, resulting in high contrast, as early as one hour post injection, both in PET and fluorescence imaging. The accumulation in non-targeted tissues was almost negligible, except in the kidneys/bladder (urinary excretion pathway). Post mortem fluorescence-guided resection confirmed high-contrast fluorescence in the NTSR1-expressing PDAC tumor model and excellent delineation of cancerous cells from surrounding tissues. The evaluation of this tracer on a more relevant orthotopic model of pancreatic cancer is in progress.

While monomodal tracers can be designed for each ap plication, we believe that introducing both modalities into a single agent, at an early stage of drug development, is a more cost-effective approach. Indeed, developing a single new chemical compound should simplify clinical translation and regulatory approval. Furthermore, it guarantees direct correlation between the diagnostic PET images used for surgical planning and the fluorescence images used during tumor resection.

These bimodal tracers should be useful to oncologists, by allowing earlier detection of PDAC primary tumors and small metastases, improving staging procedures, and tailoring of the best therapeutic strategy for each patient. For those who can benefit from surgery, the injection of the non-radioactive fluorescent tracer $\mathbf{2 a}$, should improve the quality of tumor resection, leading ultimately to increased chances of survival. Future work will focus on the transposition of this dual-labeling strategy to non-peptide antagonists of NTSR1, which exhibit promising biodistribution properties. ${ }^{41}$

\section{EXPERIMENTAL SECTION}

All chemicals were purchased from Sigma-Aldrich, Acros Organics and Alfa Aesar and used without further purification. Fmoc-protected amino acids and coupling reagents for peptide synthesis were from Iris Biotech. $(R)$ NODAGA-NHS and DOTA-NHS were provided by CheMatech (Dijon, France). The tetrasulfonated cyanine $5^{* *}$ was kindly given by Dr. Christophe Portal (EM Imaging, Edinburgh, United Kingdom). The disulfonated Cy5 and the $\mathrm{Cy} 5$ dye were provided by Pr. Anthony Romieu (ICMUB, Dijon, France). Moisture sensitive reactions were performed under nitrogen or argon atmosphere. The purity of tested compounds was determined by RPHPLC-MS and was $>95 \%$, unless specified. The synthesis of compounds 1, 2, 3 and 2a is described below. Data for other compounds are available in the Supplementary information document.

Synthesis of peptide conjugates 1, 2, and 3. Peptides were synthesized in $0.1 \mathrm{mmol}$ scale on a Liberty Blue automated microwave peptide synthesizer (CEM, USA). The synthesis was performed by using predefined Fmoc/tBu chemistry protocols on a Fmoc-Leu Wang resin (loading: $0.32 \mathrm{mmol} / \mathrm{g}$ ), with DIC and Oxyma as coupling agents, and a solution of $20 \%$ piperidine in DMF for Fmoc-deprotection steps. A solution of (R)-NODAGANHS (2 equiv.) and DIPEA (10 equiv.) in dry DMF was added to the resin-bound peptide. The reaction mixture was shaken at room temperature overnight. The resin was washed three times with $\mathrm{DMF}, \mathrm{CH}_{2} \mathrm{Cl}_{2}$ and $\mathrm{Et}_{2} \mathrm{O}$. The peptide was cleaved from the resin using TFA:triisopropylsilane: $\mathrm{H}_{2} \mathrm{O}(95: 2.5: 2.5, v / v / v, 5 \mathrm{~mL})$ for 2 $\mathrm{h}$ at room temperature. The filtrate was recovered and heated at $40^{\circ} \mathrm{C}$ for 4 additional hours and then, concentrated under a flow of nitrogen gas, followed by precipitation in diethyl ether and centrifugation $(4000 \mathrm{rpm}, 10$ minutes). The supernatant was removed and the residue was dried under vacuum.

The crude peptide was purified by semi-preparative HPLC on a BetaBasic-18 column (A: $\mathrm{H}_{2} \mathrm{O} 0.1 \%$ TFA, B: $\mathrm{MeCN} 0.1 \%$ TFA with the following gradient program: $10 \%$ to $60 \%$ of $B$ in $50 \mathrm{~min}$, at a flow rate of $20 \mathrm{~mL} / \mathrm{min}$ ) 
and the appropriate fractions were lyophilized to afford target peptides as white powders with a yield ranging from 43 to $69 \%$.

Synthesis of peptide conjugate 2a. To a solution of tetrasulfonated cyanine 5.0 Cy5 $5^{* *}$ (1.3 equiv.) in DMF was added DIPEA (7.8 equiv.) and TSTU (1.3 equiv.). The reaction mixture was stirred at room temperature for $1 \mathrm{~h}$. This solution was added to a solution of peptide (1 equiv.) and DIPEA (10 equiv.) in DMF. The reaction mixture was stirred at room temperature overnight. The solvent was removed under vacuum and the solid was purified by semi-preparative HPLC on a SiliaChrom ${ }^{\circledR}$ dt $\mathrm{C}_{18}$ column (Silicycle) (A: TEAB $50 \mathrm{mM}, \mathrm{B}: \mathrm{MeCN}$ with the following gradient program: $5 \%$ of $B$ for $10 \mathrm{~min}, 5 \%$ to $60 \%$ of $B$ in $60 \mathrm{~min}$, at a flow rate of $20 \mathrm{~mL} / \mathrm{min}$ ) to afford the target peptide 2a (triethylammonium salt) as a blue powder (15.8 mg, 23\%, purity 94\%). HRMS: $\mathrm{m} / \mathrm{z}$ calculated for $\mathrm{C}_{109} \mathrm{H}_{167} \mathrm{~N}_{21} \mathrm{O}_{33} \mathrm{~S}_{4}[\mathrm{M}+\mathrm{H}]^{+}$2427.09908, found 2427.11013.

In vitro stability. $15 \mu \mathrm{L}$ of a $5 \mathrm{mM}$ stock solution of peptide in $\mathrm{H}_{2} \mathrm{O}$ were stirred in a thermomixer $(900 \mathrm{rpm}$, $37^{\circ} \mathrm{C}$, dark) with $135 \mu \mathrm{L}$ of mouse serum (Sigma Aldrich, M5905, batch\#SLBT4412). The final concentration in peptide was $0.5 \mathrm{mM}$. After $0 \mathrm{~min}, 20 \mathrm{~min}, 35 \mathrm{~min}, 1 \mathrm{~h}, 2 \mathrm{~h}, 4 \mathrm{~h}$, $8 \mathrm{~h}$, and $24 \mathrm{~h}$, a sample $(15 \mu \mathrm{L})$ was collected and diluted with $60 \mu \mathrm{L}$ of ethanol $99 \%$. Samples were vortexed and centrifuged (11700 rpm, 10 minutes) to remove precipitated proteins. The supernatant was analyzed by RPHPLC-MS at a wavelength of $214 \mathrm{~nm}$.

In vitro binding affinity. The affinity of each bimodal compound natGa-1a, ${ }^{\text {nat } G a-2 a, ~}{ }^{\text {nat }} \mathrm{Ga}-\mathbf{3 a}$, ${ }^{\text {nat } G a-3 b}$ and ${ }^{\text {nat }} \mathrm{Ga}-$ $3 \mathbf{c}$ for the NTSR1 receptors was measured on a competitive binding assay on human recombinant $\mathrm{CHO}$ cells overexpressing NTSR1, using [125][I-Tyr ${ }^{3}$-neurotensin $\left(0.05 \mathrm{nM}, K_{\mathrm{d}}=0.22 \mathrm{nM}\right)$ as radioligand (Eurofins, France) ${ }^{34} \mathrm{IC}_{50}$ values were converted into inhibition constants $\left(K_{\mathrm{i}}\right)$ using the Cheng-Prusoff equation.

Radiolabeling. Compounds were radiolabeled using a R\&D Synchrom module (Raytest, Germany). The ${ }^{68} \mathrm{Ge} /{ }^{68} \mathrm{Ga}$ eluate $(1.5 \mathrm{~mL}, 150-300 \mathrm{MBq})$ was adjusted to $\mathrm{pH} 3.5$ with sodium acetate $(0.8 \mathrm{M})$. Each compound (9 to $12 \mathrm{nmol} ; \mathbf{1 a}, \mathbf{2 a}, \mathbf{3 a}$ as triethylammonium salts; $\mathbf{3 b}$ and $\mathbf{3 c}$ as TFA salts) was added and incubated under agitation at $40^{\circ} \mathrm{C}$ for $10 \mathrm{~min}$. The products were purified on a $\mathrm{C}_{18} \mathrm{Sep}-$ Pack cartridge (Waters Milford, USA) and eluted using $800 \mu \mathrm{L}$ of $80 \%$ ethanol in the second reactor, then subsequently evaporated at $70{ }^{\circ} \mathrm{C}$ under argon flow. The final products were diluted with $9 \mathrm{mg} / \mathrm{mL}$ sodium chloride $(\mathrm{NaCl})$. HPLC quality control was performed using a reverse-phase column (Discovery Bio, $5 \mu \mathrm{m}, 300 \AA$, Supelco) on a Waters Breeze System equipped with a 1525 binary pump. Radioactivity was detected with a Berthold radio-HPLC detector. (A: $\mathrm{H}_{2} \mathrm{O} 0.1 \%$ TFA, $\mathrm{B}: \mathrm{MeCN} 0.1 \%$ TFA with the following gradient program: $17 \%$ to $80 \%$ of $B$ in $15 \mathrm{~min}$, at a flow rate of $2 \mathrm{~mL} / \mathrm{min}$ ). The tracers were dissolved in a saline solution $(9 \mathrm{mg} / \mathrm{mL} \mathrm{NaCl})$ before injection.

Cell culture and animal models. Human pancreatic adenocarcinoma cell line AsPC-1 (ATCC, Rockville, MD, USA) were cultured in RPMI-1640 medium with $10 \%$ fetal bovine serum (FBS) in a humidified atmosphere of $5 \%$ $\mathrm{CO}_{2}$ at $37^{\circ} \mathrm{C}$.

All animal experiments were carried out in compliance with the French laws relating to the conduct of animal experimentation. The subcutaneous AsPC-1 tumors were developed by injection of $5 \times 10^{6}$ cells in a 1:1 mixture of matrigel (BD Biosciences) in the right shoulder of female immunodeficient mice (Nu/nu, Charles River, France) (56 weeks old). Animals were subjected to further imaging experiments when the tumors grew to at least $3 \mathrm{~mm}$ in diameter.

Small animal PET imaging and biodistribution studies. Healthy female adult $\mathrm{Nu} / \mathrm{nu}$ mice were weighted and intravenously injected via the retro-orbitary sinus with 3.49 $\pm 2.71 \mathrm{MBq}$ of each radiotracer based on consistent pmol injected. Dynamic PET imaging was performed immediately p.i. using the Mosaic HP Small Animal Imager (Philips) for $70 \mathrm{~min}$ with $4 \times 2 \mathrm{~min}, 2 \times 5 \mathrm{~min}$ frames with 1 min between each sinogram followed by $3 \times 10 \mathrm{~min}$ frames. The animals were kept under anesthesia using $1.5 \%$ of isoflurane from the time of ${ }^{68} \mathrm{Ga}$-labeled compounds administration until the end of imaging. All sinograms were reconstructed in 3D Standardized Uptake Value (SUV) images and visualized as Maximum Intensity Projection (MIP). Processing of reconstructed images was performed with the Syntegra-Philips software (PETView; Philips Medical Systems). For each mouse submitted to dynamic PET imaging, three-dimensional regions of interest (ROIs) were drawn manually by irregular contouring on PET images as follows: total mouse, heart, kidneys, liver and urinary bladder. The total number of voxels in a given organ was divided by the number of voxels in the "total mouse" for each frame. Data were expressed as normalized uptake in percentage injected activity per organ (\% IA) and the decay-corrected mean time-activity curves (TACs) were extracted for each target organ.

Static PET images were acquired at $40 \mathrm{~min}$ p.i. for $15 \mathrm{~min}$. After imaging, $1 \mathrm{~h}$ p.i. of $\left[{ }^{68} \mathrm{Ga}\right] \mathrm{Ga} 1 \mathrm{a},\left[{ }^{68} \mathrm{Ga}\right] \mathrm{Ga} 2 \mathbf{a}$, $\left[{ }^{68} \mathrm{Ga}\right] \mathrm{Ga} a \mathrm{a}(553 \pm 145 \mathrm{pmol}, 3.17 \pm 0.92 \mathrm{MBq})$, mice were sacrificed and main organs and tissues were dissected, washed, weighed, and gamma-counted (1480 Wizard 3, Perkin Elmer). Tumor or tissue uptake was expressed as mean \pm SD percentage injected dose per gram $(\% \mathrm{ID} / \mathrm{g})$, corrected for radionuclide decay.

Near-Infrared Fluorescence Imaging. $50 \mathrm{pmol}, 500 \mathrm{pmol}$ or $5 \mathrm{nmol}$ of 2a were injected intravenously, in $0.1 \mathrm{~mL}$ volume, in mice bearing subcutaneous AsPC- 1 tumors. After $1 \mathrm{~h}, 3 \mathrm{~h}$ or $24 \mathrm{~h}$ p.i., optical imaging was conducted in vivo, 
post mortem with the skin above the tumor removed, and ex vivo on dissected tumors and organs using the an IVIS Lumina system (PerkinElmer) with the following settings: 640 ex/680 em (Cy5.5) and 1 sec exposure time. Living Image Software (IVIS Imaging Systems, PerkinElmer) was used to display fluorescence/visible light overlays and measure average radiant efficiencies $\left(\left[\mathrm{p} / \mathrm{s} / \mathrm{cm}^{2} / \mathrm{sr}\right] /\right.$ $\left.\left[\mu \mathrm{W} / \mathrm{cm}^{2}\right]\right)$ on isolated organs.

Fluorescence-Guided Dissection. The Kaer Imaging System (KIS) 650 (Kaer Labs, Nantes, France) was used for fluorescence real time imaging during the post mortem dissection of the tumor. The system has an open design that allows for simultaneous surgery and imaging (open fluorescence). Laser excitation was applied at a wavelength of $640 \mathrm{~nm}$, and fluorescence emission was collected with a high-pass filter with a cut-off frequency of $665 \mathrm{~nm}$. Sequences were saved as series of tiff images with raw data to allow for quantification, before they were exported as movies for illustration. For each fluorescence image, an image with the laser off was subtracted from the fluorescence signal, in order to increase sensitivity and robustness to ambient light. All images (raw fluorescence, background, subtracted images and overlay color images) were displayed in real time and saved.

\section{ASSOCIATED CONTENT}

Supporting Information. Materials and general procedures; synthesis and analytical characterization of all compounds; metalation procedure with nat $\mathrm{Ga}$; in vitro stability data; radiolabeling data; tables of ex vivo biodistribution data by gamma-counting and fluorescence imaging; additional figures of fluorescence imaging; video of the fluorescenceguided resection of tumors in a mouse model; SMILES formula of each tested compound and associated biochemical data.

This material is available free of charge via the Internet at http://pubs.acs.org.

\section{AUTHOR INFORMATION}

Corresponding Authors

*A.P. : aurelie.prignon@sorbonne-universite.fr;

*V.G. : victor.goncalves@u-bourgogne.fr;

Author Contributions

All authors have given approval to the final version of the manuscript.

\section{Funding Sources}

This work was partly funded by the French National Research Agency (ANR) under the French Investissements d'Avenir programs Equipex (IMAPPI, ANR-10-EQPX-0501), France Life Imaging (FluoNTEP, ANR-11-INBS-0006), and AAP Générique 2017 (ZINELABEL, ANR-17-CE180016-01). This work was also supported by the CNRS and the Université de Bourgogne. This work is also part of the project Pharmaco-imagerie et agents théranostiques funded by the Conseil Régional de Bourgogne Franche-Comté through the Plan d'Action Régional pour l'Innovation (PARI) and by the
European Union through the PO FEDER-FSE 2014/2020 Bourgogne program.

\section{Notes}

The animal study was conducted in accordance with the legislation on the use of laboratory animals (directive 2010/63/EU) and was approved by accredited Ethical committee.

Pierre-Alix Dancer is the co-founder of the company Kaer Labs that develops and sells in vivo fluorescence imaging systems.

\section{ACKNOWLEDGMENT}

The authors thank Christophe Piesse from the "Plateforme d'Ingénierie des Protéines de Sorbonne Université, CNRS, Institut de Biologie Paris-Seine, IBPS" for help regarding the synthesis protocol of NT-20.3 and Aurélien Gibier for the synthesis of DOTA-NT-20.3. We also thank the "Plateforme d'Analyse Chimique et de Synthèse Moléculaire de l'Université de Bourgogne" (http://www.wpcm.fr) for access to analytical instrumentation and Pr. Anthony Romieu for providing Cy5 and the disulfonated cyanine 5 .

\section{ABBREVIATIONS}

AEEAc, 8-amino-3,6-dioxaoctanoic acid; CHO, Chinese hamster ovary; Cy5, Cyanine 5; DOTA, 1,4,7,10-tetraazacyclododecane-1,4,7,10-tetraacetic acid; FGS, fluorescenceguided surgery; NIR, near infra-red; $(R)-N O D A G A,(R)$ 1,4,7-triazacyclononane,1-glutaric acid-4,7-acetic acid; NT, neurotensin; NTSR1, neurotensin receptor 1; PBS, Phosphate buffer saline; PDAC, pancreatic ductal adenocarcinoma; PET, positron emission tomography; TEAB, Triethylammonium bicarbonate.

\section{REFERENCES}

(1) Carrato, A.; Falcone, A.; Ducreux, M.; Valle, J. W.; Parnaby, A.; Djazouli, K.; Alnwick-Allu, K.; Hutchings, A.; Palaska, C.; Parthenaki, I. A Systematic Review of the Burden of Pancreatic Cancer in Europe: Real-World Impact on Survival, Quality of Life and Costs. J. Gastrointest. Canc. 2015, 46, 201-211.

(2) Hidalgo, M.; Cascinu, S.; Kleeff, J.; Labianca, R.; Lohr, J. M.; Neoptolemos, J.; Real, F. X.; Van Laethem, J. L.; Heinemann, V. Addressing the Challenges of Pancreatic Cancer: Future Directions for Improving Outcomes. Pancreatology 2015, 15, 8-18.

(3) Saad, A. M.; Turk, T.; Al-Husseini, M. J.; AbdelRahman, O. Trends in Pancreatic Adenocarcinoma Incidence and Mortality in the United States in the Last Four Decades; a SEER-Based Study. BMC Cancer 2018, 18, 688.

(4) La Torre, M.; Nigri, G.; Lo Conte, A.; Mazzuca, F.; Tierno, S. M.; Salaj, A.; Marchetti, P.; Ziparo, V.; Ramacciato, G. Is a Preoperative Assessment of the Early Recurrence of Pancreatic Cancer Possible After Complete Surgical Resection? Gut Liver 2014, 8, 102-108.

(5) Neoptolemos, J. P.; Stocken, D. D.; Dunn, J. A.; Almond, J.; Beger, H. G.; Pederzoli, P.; Bassi, C.; Dervenis, C.; Fernandez-Cruz, L.; Lacaine, F.; Buckels, J.; Deakin, M.; Adab, F. A.; Sutton, R.; Imrie, C.; Ihse, I.; Tihanyi, T.; Olah, A.; Pedrazzoli, S.; Spooner, D.; Kerr, D. J.; Friess, H.; Buchler, M. W. Influence of Resection Margins on Survival for Patients with Pancreatic Cancer Treated by Adjuvant Chemoradiation and/or 
Chemotherapy in the ESPAC-1 Randomized Controlled Trial. Ann. Surg. 2001, 234, 758-768.

(6) Vaquero, J. J.; Kinahan, P. Positron Emission Tomography: Current Challenges and Opportunities for Technological Advances in Clinical and Preclinical Imaging Systems. Annu. Rev. Biomed. Eng. 2015, 17, 385-414.

(7) Nagaya, T.; Nakamura, Y. A.; Choyke, P. L.; Kobayashi, H. Fluorescence-Guided Surgery. Front. Oncol. 2017, $7,314$.

(8) Hernandez Vargas, S.; Ghosh, S. C.; Azhdarinia, A. New Developments in Dual-Labeled Molecular Imaging Agents. J. Nucl. Med. 2019, 60, 459-465.

(9) Xi, L.; Jiang, H. Image-Guided Surgery Using Multimodality Strategy and Molecular Probes. Wiley Interdiscip. Rev. Nanomed. Nanobiotechnol. 2016, 8, 46-60.

(10) Zhao, J.; Chen, J.; Ma, S.; Liu, Q.; Huang, L.; Chen, X.; Lou, K.; Wang, W. Recent Developments in Multimodality Fluorescence Imaging Probes. Acta Pharm. Sin. B 2018, 8, 320-338.

(11) Seibold, U.; Wängler, B. r.; Schirrmacher, R.; Wängler, C. Bimodal Imaging Probes for Combined PET and OI: Recent Developments and Future Directions for Hybrid Agent Development. BioMed Res. Int. 2014, 13 pages.

(12) Azhdarinia, A.; Ghosh, P.; Ghosh, S.; Wilganowski, N.; Sevick-Muraca, E. M. Dual-Labeling Strategies for Nuclear and Fluorescence Molecular Imaging: a Review and Analysis. Mol. Imaging Biol. 2012, 14, 261-276.

(13) Wu, Z.; Martinez-Fong, D.; Tredaniel, J.; Forgez, P Neurotensin and its High Affinity Receptor 1 as a Potential Pharmacological Target in Cancer Therapy. Front. Endocrinol. 2013,3.

(14) Körner, M.; Waser, B.; Strobel, O.; Büchler, M.; Reubi, J. C. Neurotensin Receptors in Pancreatic Ductal Carcinomas. EJNMMI Res. 2015, 5, 17.

(15) Reubi, J. C.; Waser, B.; Friess, H.; Buchler, M.; Laissue, J. Neurotensin Receptors: a New Marker for Human Ductal Pancreatic Adenocarcinoma. Gut. 1998, 42, 546-550.

(16) Yin, X.; Wang, M.; Wang, H.; Deng, H.; He, T.; Tan, Y.; Zhu, Z.; Wu, Z.; Hu, S.; Li, Z. Evaluation of Neurotensin Receptor 1 as a Potential Imaging Target in Pancreatic Ductal Adenocarcinoma. Amino Acids 2017, 49, 1325-1335.

(17) De Visser, M.; Janssen, P. J.; Srinivasan, A.; Reubi, J. C.; Waser, B.; Erion, J. L.; Schmidt, M. A.; Krenning, E. P.; De Jong, M. Stabilised 111In-Labelled DTPA- and DOTA-Conjugated Neurotensin Analogues for Imaging and Therapy of Exocrine Pancreatic Cancer. Eur. J. Nucl. Med. Mol. Imaging 2003, 30, 11341139.

(18) Krumm, B. E.; Lee, S.; Bhattacharya, S.; Botos, I.; White, C. F.; Du, H.; Vaidehi, N.; Grisshammer, R. Structure and Dynamics of a Constitutively Active Neurotensin Receptor. Sci. Rep. 2016.

(19) Myers, R. M.; Shearman, J. W.; Kitching, M. O.; RamosMontoya, A.; Neal, D. E.; Ley, S. V. Cancer, Chemistry, and the Cell: Molecules that Interact with the Neurotensin Receptors. ACS Chem. Biol. 2009, 4, 503-525.

(20) Kokko, K. P.; Hadden, M. K.; Orwig, K. S.; Mazella, J.; Dix, T. A. In Vitro Analysis of Stable, Receptor-Selective Neurotensin[8-13] Analogues. J. Med. Chem. 2003, 46, 4141-4148.

(21) Alshoukr, F.; Rosant, C.; Maes, V.; Abdelhak, J.; Raguin, O.; Burg, S.; Sarda, L.; Barbet, J.; Tourwé, D.; Pelaprat, D.; Gruaz-Guyon, A. Novel Neurotensin Analogues for Radioisotope Targeting to Neurotensin Receptor-Positive Tumors. Bioconjugate Chem. 2009, 20, 1602-1610.
(22) Alshoukr, F.; Prignon, A.; Brans, L.; Jallane, A.; Mendes, S.; Talbot, J.-N.; Tourwé, D.; Barbet, J.; Gruaz-Guyon, A. Novel DOTA-Neurotensin Analogues for 111In Scintigraphy and 68Ga PET Imaging of Neurotensin Receptor-Positive Tumors. Bioconjugate Chem. 2011, 22, 1374-1385.

(23) Prignon, A.; Provost, C.; Alshoukr, F.; Wendum, D.; Couvelard, A.; Barbet, J.; Forgez, P.; Talbot, J.-N.; Gruaz-Guyon, A. Preclinical Evaluation of 68Ga-DOTA-NT-20.3: A Promising PET Imaging Probe To Discriminate Human Pancreatic Ductal Adenocarcinoma from Pancreatitis. Mol. Pharmaceutics 2019, 16, 2776-2784.

(24) Deng, H.; Wang, H.; Wang, M.; Li, Z.; Wu, Z. Synthesis and Evaluation of 64Cu-DOTA-NT-Cy5.5 as a Dual-Modality PET/Fluorescence Probe to Image Neurotensin ReceptorPositive Tumor. Mol. Pharmaceutics 2015, 12, 3054-3061.

(25) Dearling, J. L. J.; Voss, S. D.; Dunning, P.; Snay, E.; Fahey, F.; Smith, S. V.; Huston, J. S.; Meares, C. F.; Treves, S. T.; Packard, A. B. Imaging Cancer Using PET-the Effect of the Bifunctional Chelator on the Biodistribution of a (64)Cu-Labeled Antibody. Nucl. Med. Biol. 2011, 38, 29-38.

(26) Marenco, M.; Lodola, L.; Persico, M. G.; Frangipane, V.; Facoetti, A.; Aprile, C.; Hodolic, M. Evidence of (68)GaDOTA-NT-20.3 Uptake in Pancreatic Adenocarcinoma AsPC-1 Cell Line - in vitro Study. Curr. Pharm. Biotechnol. 2018, 19, 754759.

(27) Brandt, M.; Cardinale, J.; Aulsebrook, M. L.; Gasser, G.; Mindt, T. L. An Overview of PET Radiochemistry, Part 2: Radiometals. J. Nucl. Med. 2018, 59, 1500-1506.

(28) Fani, M.; Del Pozzo, L.; Abiraj, K.; Mansi, R.; Tamma, M. L.; Cescato, R.; Waser, B.; Weber, W. A.; Reubi, J. C.; Maecke, H. R. PET of Somatostatin Receptor-Positive Tumors Using 64Cu- and 68Ga-Somatostatin Antagonists: The Chelate Makes the Difference. J. Nucl. Med. 2011, 52, 1110-1118.

(29) Gourni, E.; Canovas, C.; Goncalves, V.; Denat, F.; Meyer, P. T.; Maecke, H. R. (R)-NODAGA-PSMA: A Versatile Precursor for Radiometal Labeling and Nuclear Imaging of PSMA-Positive Tumors. PLoS One 2015, 10, e0145755.

(30) Pisoni, D. S.; Todeschini, L.; Borges, A. C. A.; Petzhold, C. L.; Rodembusch, F. S.; Campo, L. F. Symmetrical and Asymmetrical Cyanine Dyes. Synthesis, Spectral Properties, and BSA Association Study. J. Org. Chem. 2014, 79, 5511-5520.

(31) Mujumdar, R. B.; Ernst, L. A.; Mujumdar, S. R.; Lewis, C. J.; Waggoner, A. S. Cyanine Dye Labeling Reagents: Sulfoindocyanine Succinimidyl Esters. Bioconjugate Chem. 1993, $4,105-111$.

(32) Canovas, C.; Moreau, M.; Bernhard, C.; Oudot, A.; Guillemin, M.; Denat, F.; Goncalves, V. Site-Specific Dual Labeling of Proteins on Cysteine Residues with Chlorotetrazines. Angew. Chem. Int. Ed. 2018, 57, 10646-10650.

(33) Canovas, C.; Moreau, M.; Vrigneaud, J. M.; Bellaye, P. S.; Collin, B.; Denat, F.; Goncalves, V. Modular Assembly of Multimodal Imaging Agents through an Inverse Electron Demand Diels-Alder Reaction. Bioconjugate Chem. 2019, 30, 888897.

(34) Burggraaf, J.; Kamerling, I. M.; Gordon, P. B.; Schrier, L.; de Kam, M. L.; Kales, A. J.; Bendiksen, R.; Indrevoll, B.; Bjerke, R. M.; Moestue, S. A.; Yazdanfar, S.; Langers, A. M.; SwaerdNordmo, M.; Torheim, G.; Warren, M.; Morreau, H.; Voorneveld, P.; Buckle, T.; van Leeuwen, F. W.; Odegardstuen, L. I.; Dalsgaard, G. T.; Healey, A.; Hardwick, J. C. Detection of Colorectal Polyps in Humans Using an Intravenously 
Administered Fluorescent Peptide Targeted Against c-Met. Nat. Med. 2015, 21, 955-961.

(35) Coin, I.; Beyermann, M. Bienert, M. Solid-Phase Peptide Synthesis: from Standard Procedures to the Synthesis of Difficult Sequences. Nat. Protoc. 2007, 2, 3247-3256.

(36) Vita, N.; Laurent, P. Lefort, S.; Chalon, P.; Dumont, X.; Kaghad, M.; Gully, D.; Le Fur, G.; Ferrara, P.; Caput, D. Cloning and Expression of a Complementary DNA Encoding a High Affinity Human Neurotensin Receptor. FEBS Lett. 1993, 317, 139142.

(37) Andrés, A.; Rosés, M.; Ràfols, C.; Bosch, E.; Espinosa, S.; Segarra, V.; Huerta, J. M. Setup and Validation of Shake-Flask Procedures for the Determination of Partition Coefficients $(\log D)$ from Low Drug Amounts. Eur. J. Pharm. Sci. 2015, 76, 181191.

(38) Maschauer, S.; Einsiedel, J.; Hübner, H.; Gmeiner, P.; Prante, O. 18F- and 68Ga-Labeled Neurotensin Peptides for PET
Imaging of Neurotensin Receptor 1. J. Med. Chem. 2016, 59, 64806492.

(39) Maschauer, S.; Ruckdeschel, T.; Tripal, P.; Haubner, R.; Einsiedel, J.; Hübner, H.; Gmeiner, P.; Kuwert, T.; Prante, O. In Vivo Monitoring of the Antiangiogenic Effect of Neurotensin Receptor-Mediated Radiotherapy by Small-Animal Positron Emission Tomography: A Pilot Study. Pharmaceuticals 2014, 7, 464-481.

(40) Bunschoten, A.; van Willigen, D. M.; Buckle, T.; van den Berg, N. S.; Welling, M. M.; Spa, S. J.; Wester, H.-J.; van Leeuwen, F. W. B. Tailoring Fluorescent Dyes To Optimize a Hybrid RGD-Tracer. Bioconjugate Chem. 2016, 27, 1253-1258.

(41) Schulz, J.; Rohracker, M.; Stiebler, M.; Goldschmidt, J.; Grosser, O. S.; Osterkamp, F.; Pethe, A.; Reineke, U.; Smerling, C.; Amthauer, H. Comparative Evaluation of the Biodistribution Profiles of a Series of Nonpeptidic Neurotensin Receptor-1 Antagonists Reveals a Promising Candidate for Theranostic Applications. J. Nucl. Med. 2016, 57, 1120-1123. 
Table of Contents Graphic
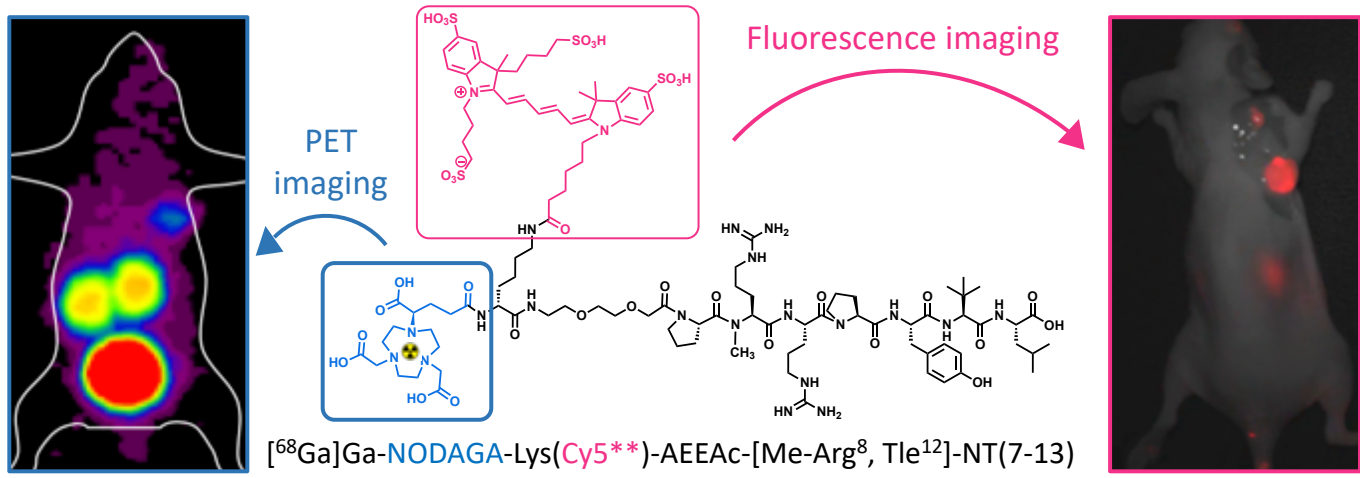